\title{
Efeito do processamento de defumação na qualidade de bijupirá (Rachycentron canadum): atributos bacteriológicos, químicos e sensoriais
}

[Effect of smoking-method on the keeping quality of cobia (Rachycentron canadum): bacteriological, chemical and sensory attributes]

\section{F.A.A. Calixto ${ }^{1}$, G.E.A. Dias ${ }^{1}$, K.R.P. Schmalz ${ }^{2}$, L.E. Silva ${ }^{3}$, S. Kajishima ${ }^{3}$, R.M. Franco ${ }^{3}$, J.T.P. Latini ${ }^{4}$, E.F.M. Mesquita ${ }^{3}$}

${ }^{1}$ Fundação Instituto de Pesca do Estado do Rio de Janeiro - Niterói, RJ

${ }^{2}$ Aluno de pós-graduação - Universidade Federal Fluminense - Niterói, RJ

${ }^{3}$ Universidade Federal Fluminense - Niterói, RJ

${ }^{4}$ Universidade Federal do Rio de Janeiro - Macaé, RJ

F.A.A. Calixto1 https://orcid.org/0000-0001-6851-7899 G.E.A. Dias1 https://orcid.org/ https://orcid.org/0000-0002-7528-2124 R.M. Franco3 https://orcid.org/0000-0003-0003-2961 J.T.P. Latini4 https://orcid.org/0000-0001-9528-1252 E.F.M. Mesquita3

https://orcid.org/0000-0003-4176-2522

\section{RESUMO}

O objetivo do presente trabalho foi desenvolver a carne de bijupirá defumada, assim como avaliar o rendimento, a qualidade bacteriológica, a composição centesimal e a aceitabilidade do produto. Análises microbiológicas de pesquisa de Salmonella sp. e contagens de Staphylococcus aureus, coliformes totais e Escherichia coli foram realizadas. Foi determinada a composição centesimal e realizado o teste de aceitação do produto. O rendimento médio da carne após a salga foi de $83,41 \%$, com base no peso do charuto. A análise microbiológica da carne defumada apresentou-se positiva em apenas uma amostra para Staphylococcus aureus e negativa para as demais bactérias. O produto possui boa qualidade nutricional e alcançou $97 \%$ de aceitação para o aspecto global, atingindo média de 6,26 $( \pm 0,99)$. A carne de bijupirá defumada obteve condições higiênico-sanitárias satisfatórias, boa qualidade nutricional, além de alto índice de aceitação sensorial, destacando-se os atributos textura e sabor. Evidenciou-se, assim, que esse tipo de processo pode ser realizado em escala artesanal ou industrial.

Palavras-chave:Rachycentron canadum, defumação a quente, padrões microbiológicos, composição nutricional, aceitação

\begin{abstract}
The objective of the study was to develop the smoked cobia meat and to evaluate the yield, the bacteriological quality, the centesimal composition, and the acceptability of the product. Microbiological analysis of Salmonella sp. and Staphylococcus aureus, total coliforms and Escherichia coli counts were performed. The centesimal composition was determined and the acceptance test was performed. The average yield of the product after salting was $83.41 \%$ based on the fish roll weight. The microbiological analysis of the smoked meat showed positive in only one sample for Staphylococcus aureus and negative for the other bacteria. The product has a good nutritional quality and was accepted obtaining $97 \%$ for the overall aspect, average of $6.26( \pm 0.99)$. The smoked cobia meat obtained satisfactory hygienicsanitary conditions, good nutritional quality, besides a high index of sensorial acceptance emphasizing the texture and flavor attributes. Smoked process can be easily carried out on an artisanal or industrial scale.
\end{abstract}

Keywords:Rachycentrum canadum, hot smoking method, microbiological standards, nutritional composition, acceptance

Recebido em 31 de outubro de 2017

Aceito em 9 de março de 2018

E-mail: flaviacalixto1@gmail.com 


\section{INTRODUÇÃO}

A criação comercial do bijupirá iniciou-se em Taiwan na década de 90 (Liao et al., 2004), sendo atualmente considerada uma espécie emergente no cenário mundial da aquicultura. Sua produção expandiu-se para os países asiáticos vizinhos, como Vietnã, Filipinas e sudeste da China, com posterior expansão para a Oceania, África, América Central e do Sul (Kaiser e Holt, 2005). A espécie apresenta um filé branco, firme, com poucas espinhas e sabor agradável.

A experiência no estado do Rio de Janeiro ainda é incipiente, porém com bons resultados experimentais de engorda, mostrando um grande potencial de desenvolvimento da espécie nessa região.

No intuito de melhorar a qualidade do pescado, uma vez que provoca mudanças nos seus atributos sensoriais, como odor, sabor, coloração e textura (Sigurgisladottir et al., 2000), tem-se utilizado o processo de defumação, que, segundo a legislação brasileira, confere cheiro e sabor característico e prolonga a vida útil do pescado, por ser parcialmente desidratado (Brasil, 1952).

Para avaliar a qualidade do pescado e de derivados, os laboratórios empregam métodos para as análises sensoriais, físico-químicas, microbiológicas e microscópicas (AlmeidaMuradian e Penteado, 2007). Pelos métodos microbiológicos, define-se, por exemplo, se o produto está próprio para consumo; e pelos físico-químicos, avalia-se a sua qualidade nutricional. Porém, o produto pode ter boa qualidade microbiológica e nutricional e não ser aceito pelo consumidor por ter, por exemplo, um sabor ruim, uma textura firme demais ou até mesmo uma aparência pouco atrativa.

Com isso, a análise sensorial é realizada em função das respostas transmitidas pelos indivíduos às várias sensações que se originam de reações fisiológicas em resposta a estímulos, gerando a interpretação das propriedades intrínsecas aos produtos. Para tanto, é preciso que haja entre as partes, indivíduos e produtos, contato e interação (Métodos..., 2008).

Assim, o objetivo do presente trabalho foi desenvolver a carne de bijupirá defumada, assim como quantificar seu rendimento, testar sua qualidade bacteriológica, sua composição centesimal e sua aceitabilidade.

\section{MATERIAL E MÉTODOS}

O experimento foi realizado com amostras de bijupirá (Rachycentrum canadum) provenientes de cultivos em tanques-rede localizados na Baía de Ilha Grande, Angra dos Reis. O produto foi adquirido diretamente dos produtores, que entregaram os peixes inteiros, em caixa isotérmica com gelo, abatidos em sua propriedade seguindo a sua rotina de comercialização. Os peixes são abatidos e comercializados inteiros ou eviscerados pelos produtores, com tamanho comercial em torno de 3 a $4 \mathrm{~kg}$.

As amostras foram transportadas em caixas isotérmicas e embaladas como normalmente se faz na rotina de comercialização do produtor até o Laboratório do Pescado e Sanidade de Aquáticos da UFF. Os exemplares foram eviscerados, as cabeças foram cortadas, os rins retirados, permanecendo o corte "charuto", que foi levemente espalmado. Além disso, os peixes foram pesados eviscerados, pesados descabeçados e após o processo, para fins de cálculo do rendimento do processo.

Os peixes eviscerados e descabeçados foram submetidos ao processo de salga úmida, por uma hora. Durante esse período, ficaram imersos na solução salina saturada em temperatura de refrigeração. A salmoura foi preparada com água potável e mistura de sais grosso e fino (1:1), atingindo $23 \mathrm{Be}$. Depois, os peixes foram levados ao defumador e submetidos ao processo de defumação a quente por quatro horas (defumador em aço inox, capacidade: 30L, Metalúrgica Lisboa Ltda.®). O tempo de defumação foi dividido em três faixas de temperatura: a $\pm 60^{\circ} \mathrm{C}, \mathrm{a} \pm 70^{\circ} \mathrm{C}$ a cada hora; e, nas últimas duas horas, $\mathrm{a} \pm 85^{\circ} \mathrm{C}$.

Com a intenção de avaliar a qualidade bacteriológica da carne do bijupirá defumada, realizaram-se análises mediante a utilização de placas Petrifilm ${ }^{\mathrm{TM}}$ adquiridas da empresa $3 \mathrm{M}$, a fim de se pesquisar Salmonella sp. e realizar as contagens de Staphylococcus aureus, coliformes totais e Escherichia coli. Para cada análise bacteriana, foi realizada metodologia específica, 
seguindo métodos oficiais aprovados da AOAC®, de acordo com os manuais de instrução cedidos pela empresa 3M (3M Food Safety Method, 2013; 3M Petrifilm ${ }^{\mathrm{TM}}$, 2013a; 3M Petrifilm $^{\mathrm{TM}}$, 2013b).

O percentual de umidade, proteína bruta, matéria mineral (cinzas) do produto defumado foi determinado segundo metodologia oficial da AOAC (Official..., 1990), em triplicata, e realizou-se a média dos resultados. Para a determinação de lipídeos totais, foi utilizada a metodologia de Folch et al. (1957). Os carboidratos (extrativo não nitrogenado) foram calculados pela fração "NIFEXT" ("Nitrogen Free Extract"), tendo como parâmetro a diferença entre $100 \%$ das demais frações da composição centesimal (Oliveira et al., 1999).

Com base nos valores de carboidratos, proteínas e lipídeos, foi calculado o valor energético total (VET) dos alimentos, sabendo-se que os carboidratos e as proteínas fornecem $4 \mathrm{kcal} / \mathrm{g}$ de energia e os lipídeos, 9kcal/g (Food..., 2005).

O teste de aceitação foi realizado no Laboratório de Análise Sensorial da Faculdade de Nutrição Emília de Jesus Ferreiro da UFF e foi aplicado como parte do projeto "Análise sensorial de alimentos e bebidas", aprovado pelo Comitê de Ética em Pesquisa da Faculdade de Medicina / Hospital Universitário Antônio Pedro - CEP CMM/HUAP no 066/07 - CAAE n. 0054.0.258.000-07.

Todos os voluntários receberam e assinaram previamente um termo de consentimento livre e esclarecido, garantindo a sua aceitação para participar do teste, que foi realizado com provadores não treinados, estudantes e funcionários da UFF, de ambos os sexos, segundo metodologia de Dutcosky (2011), em cabines individuais, sob a luz branca e em temperatura ambiente, utilizando-se escala hedônica de sete pontos. Observações poderiam ser apontadas pelos julgadores em local próprio, na ficha. Foi indagado sobre a intenção de compra do produto, a qual foi dividida em escala de cinco pontos: decididamente compraria, provavelmente compraria, talvez sim/ talvez não, provavelmente eu não compraria, decididamente eu não compraria.
O peixe defumado foi cortado em amostras de aproximadamente $30 \mathrm{~g}$, que foram assadas em forno pré-aquecido à temperatura de $180^{\circ} \mathrm{C}$, por 15min. As amostras foram servidas à temperatura ambiente, para que o calor não alterasse muito o sabor.

Nos resultados obtidos pelo método da escala hedônica, as categorias descritivas foram transformadas nos valores numéricos correspondentes; as amostras foram aceitas se $70 \%$ dos provadores atribuíram nota $\geq 4$.

Os escores dos atributos foram descritos estatisticamente por meio dos parâmetros: média, desvio-padrão e dos parâmetros de ordem (valor mínimo e máximo, mediana e amplitude interquartílica), representados graficamente por diagramas de hastes e caixa ("box-and-whiskers plot"). Foi empregado, para avaliação de normalidade dos escores, o teste de KolmogorvSmirnov. Para comparações múltiplas entre os atributos, utilizou-se o pós-teste de Friedmann, com significância corrigida pelo critério de Bonferroni a 5\% ( $\alpha=0,05)$. O software estatístico PWSD (ex-SPSS), versão 18.0, foi usado como suporte para as análises estatísticas.

\section{RESULTADOS E DISCUSSÃO}

O rendimento médio do produto após a defumação foi de $64,21 \%$, com base no peso do animal eviscerado, e de $83,41 \%$, com base no peso do charuto, o que mostrou ser um ótimo rendimento. A perda de peso ocorrida no processo de defumação está de acordo com a literatura. Sigurgisladottir et al. (2000) afirmam que essas perdas podem variar de 10 a $25 \%$, dependendo do tipo de material in natura, das características do produto final e dos parâmetros usados no processo, tais como o tempo e a temperatura. Souza (2003) associa a perda de peso no processo de defumação à desidratação proporcionada com a elevação de temperatura no processo e encontrou perdas entre 14,56\% e $16,75 \%$ em defumação a quente de filés de tilápia-do-nilo com e sem pele, resultado semelhante ao presente trabalho.

A carne defumada apresentou média de 0,6UFC/g para a contagem de Staphylococcus aureus. Para as análises de coliformes totais, Escherichia coli e Salmonella spp., não houve crescimento bacteriano em todas as amostras. 
Assim, o processamento de conservação foi ótimo quanto à qualidade microbiológica do produto.

O padrão da legislação brasileira (Brasil, 2001) para pescado seco e/ou salgado e para pescado defumado é de $10^{2}$ para coliformes termotolerantes por grama de pescado, de $5 \times 10^{2}$ para Staphylococcus coagulase positiva/g e de ausência de Salmonella sp./25g. O método utilizado é mais específico do que a legislação brasileira, pois realiza contagem de E. coli em vez de coliformes termotolerantes e de $S$. aureus em vez de coagulase positiva, espécies essas maiores indicadoras das condições higiênicosanitárias dos produtos. Pelo resultado, o produto apresentou excelente condições bacteriológicas se comparado ao padrão prescrito pela legislação brasileira. Igualmente, Costa et al. (2008), que trabalharam defumação líquida em filés de piauvermelho, obtiveram todas as amostras dentro do padrão estabelecido pela legislação, assim como Gonçalves et al. (2014), que defumaram posta e filé de bijupirá.

Quanto à composição centesimal e ao valor energético total da carne de bijupirá defumada, os resultados estão apresentados na Tab. 1 .

Tabela 1. Resultados médios da composição centesimal e valor energético da carne de bijupirá (Rachycentron canadum) defumada

\begin{tabular}{cc}
\hline Componente nutricional & Médias da triplicata \\
\hline Umidade & $58,84 \%$ \\
Proteína bruta & $20,64 \%$ \\
Lipídeo bruto & $15,05 \%$ \\
Matéria mineral & $4,38 \%$ \\
Extrativo não & $1,09 \%$ \\
nitrogenado & $222 \mathrm{kcal} / \mathrm{g}$ \\
Valor energético total &
\end{tabular}

$\mathrm{O}$ teor de umidade no produto manteve-se abaixo de $65 \%$, que é o recomendado para produtos defumados (Morais et al., 1996).

Gonçalves et al. (2014) determinaram a composição centesimal de bijupirá in natura (IN) e do filé de bijupirá defumado (FD) e encontraram valores diferentes, sobretudo em umidade, lipídeos totais e proteínas. Os valores de umidade se apresentaram maiores que os da presente pesquisa, $75,09 \%$ (IN) e 64,85\% (FD), o que era esperado, visto que o processo de defumação a reduz, porém esse resultado não era esperado para o produto defumado, pois os autores usaram o mesmo método de defumação a quente descrito neste trabalho. Em relação ao percentual de proteína, o do presente trabalho foi um pouco inferior ao apresentado por esses autores, $21,42 \%$ (IN) e 25,19\% (FD). Os valores de lipídeos foram bem menos expressivos, $1,92 \%$ (IN) e 4,26\% (FD), comparados aos $15,05 \%$ do trabalho aqui apresentado, o que está, provavelmente, associado com a redução da umidade. Isso torna as outras frações percentualmente maiores. $\mathrm{O}$ teor de matéria mineral se apresentou semelhante nos dois produtos defumados: do presente estudo $(4,38 \%)$ e do filé defumado $(4,52 \%)$. Os mesmos autores, entretanto, apresentaram resultado inferior $(1,39 \%)$ de cinzas para a carne in natura. Igualmente, esta diferença se deve ao fato de o produto defumado sofrer etapa de salga e, além disso, redução de umidade em seu processamento.

A composição encontrada na carne defumada se mostrou diferente do relatado por outros autores para carne de bijupirá, sobretudo pelo teores de proteínas inferior e lipídeos bem superrior e que, consequentemente, leva a uma alteração no valor energético total quando comparado com números apresentados por Franco (1998), que afirmou que o bijupirá tem como composição centesimal 26,2g de proteína, 2,1g de lipídeos, 8,0mg de cálcio, $220 \mathrm{mg}$ de fósforo, 4,0mg de ferro, totalizando 131 calorias em $100 \mathrm{~g}$ do produto.

Ackman (1989) dividiu os peixes em quatro categorias quanto ao seu teor de lipídeos: magro (inferior a $2 \%$ de gordura); baixo teor de gordura (2-4\% de gordura); semigordo $(4-8 \%$ de gordura); e altamente gordo (superior a $8 \%$ de gordura). Assim, diferentemente dos outros relatos, o bijupirá defumado do presente trabalho tem maior percentual de lipídeos, não apenas por ser um animal de cativeiro, mas também pelo processo de redução da umidade.

Segundo Souza (2003), o aumento dos teores de proteínas e de lipídeos, observado nos filés defumados de tilápia-do-nilo em relação aos in natura, resulta da desidratação ocorrida em razão do processamento de defumação. Sigurgisladottir et al. (2000) afirmam que há essa mudança principalmente pela relativa perda de umidade, decorrente do processo de desidratação do músculo durante a defumação. Além disso, Shiau 
e Chai (1985) e Gonçalves e Prentice-Hernández (1998) observaram que a absorção de sal durante o processo de salmouragem antes da defumação acarreta um aumento de teores de cinza no pescado defumado. Esses fatores podem explicar o alto percentual de gordura e minerais que o produto apresentou no estudo atual.

Ademais, para a análise sensorial, o total de provadores foi de 100 pessoas, sendo $77 \%$ do sexo feminino e $23 \%$ do sexo masculino, de idade entre 19 e 60 anos. Igualmente, em trabalho de Coelho et al. (2010), a maioria dos provadores não treinados que avaliaram filés de carpa e tilápia defumados era do sexo feminino. O produto foi aceito com $97 \%$ para o aspecto global, atingindo média de 6,26 $( \pm 0,99)$.

Trabalhos com defumação de outras espécies por meio do uso de fumaça líquida têm conseguido maior percentual de aceitação em comparação ao presente estudo. Gonçalves e Prentice-Hernandez (1998), ao trabalharem com defumação líquida em anchova, obtiveram aceitabilidade de 100\% dos julgadores, resultado superior ao aqui apresentado (97\%), igualmente a Gonçalves e Cezarini (2008), ao defumarem jundiá com fumaça líquida. Porém esses mesmos autores, quando defumaram de maneira tradicional, obtiveram piores resultados: $91 \%$ de aceitação e média na escala hedônica entre indiferente e gostei ligeiramente. A média do presente trabalho ficou entre gostei muito e moderadamente. Este fator pode ser atribuído ao hábito atual da sociedade, que consome produtos defumados industrialmente por adição de fumaça líquida, em vez da defumação tradicional.

As médias das notas dadas aos atributos odor, cor, textura e sabor estão descritas na Tab. 2 e na Fig. 1, sendo a textura a categoria mais bem avaliada e o odor a menos apreciada.

Ferreira et al. (2012) defumaram pintado (Pseudoplatystoma corruscans) e "catfish" (Ictalurus punctatus) por meio de fumaça líquida e avaliaram sensorialmente em uma escala de nove pontos. Obtiveram médias semelhantes às do presente trabalho, com valores entre as duas melhores atribuições na escala hedônica, exceto para o atributo odor do pintado defumado, que se apresentou entre a segunda e a terceira nota na escala.

A Figura 2 e a Tab. 3 resumem os achados. Observa-se que há diferença estatística entre a categoria odor e as categorias textura e sabor, tendo estas apresentado melhores resultados.

Pesquisa realizada com consumidores de pescado em Santo André, São Paulo, mostra que a maioria dos consumidores de pescado está habituada com o cheiro característico de peixe e, por isso, não é um fator limitante para o seu consumo. Após escolha por essa carne, os consumidores entendem que se trata de um cheiro característico, não sendo capaz de discriminá-lo (Vasconcellos, 2010); este resultado sugere, assim, que a menor média atribuída para o odor não seria capaz de evitar o consumo do bijupirá defumado.

Tabela 2. Resumo da estatística descritiva do teste de aceitação da carne de bijupirá (Rachycentron canadum) defumada

\begin{tabular}{cccccccc}
\hline Atributos & $\mathrm{N}$ & Média & d.p. $(*)$ & Mín. & Máx. & Mediana & i.q.r. $(*)$ \\
\hline Odor & 99 & 5,8 & 2,02 & 2 & 7 & 6 & 2 \\
Cor & 100 & 6,1 & 1,13 & 3 & 7 & 6 & 1 \\
Textura & 100 & 6,3 & 1,08 & 2 & 7 & 7 & 1 \\
Sabor & 100 & 6,2 & 1,42 & 1 & 7 & 7 & 1 \\
\hline
\end{tabular}

*d.p.: desvio-padrão; i.q.r.: intervalo interquartil. 


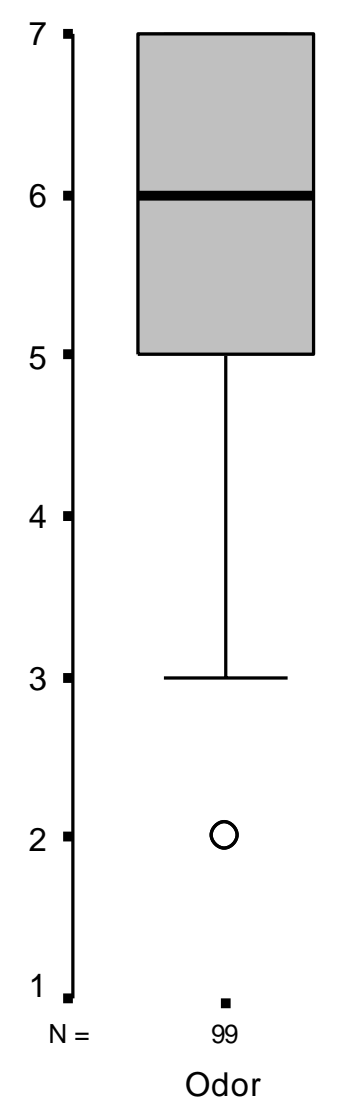

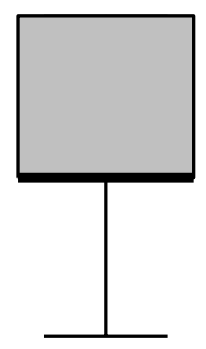

O

*

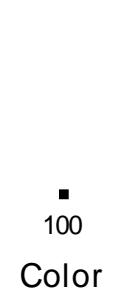

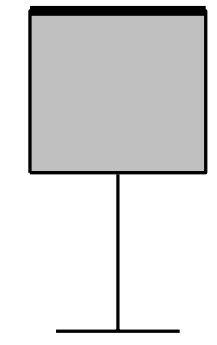

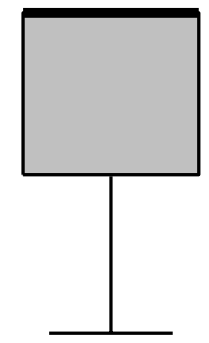

0

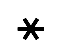

*

100

Texture
*

*

$*$
100

0

Taste

Attihı ıtes

Figura 1. Diagrama em caixas e hastes indicando as notas atribuídas, no eixo vertical, pelas categorias avaliadas, no eixo horizontal, pela análise sensorial da carne de bijupirá (Rachycentron canadum) defumada.

\begin{tabular}{|c|c|c|c|}
\hline Atributos & Cor & Textura & Sabor \\
\hline Odor & $\begin{array}{c}\mathrm{z}=-2.427 \\
\mathrm{p} \text {-value }=.014 \\
\text { NO }\end{array}$ & $\begin{array}{c}\mathrm{z}=-3.683 \\
\mathrm{p} \text {-value }=.0001 \\
\text { YES }\end{array}$ & $\begin{array}{c}\mathrm{z}=-3.402 \\
\mathrm{p} \text {-value }=.0005 \\
\text { YES }\end{array}$ \\
\hline Cor & & $\begin{array}{c}\mathrm{z}=-1.167 \\
\mathrm{p} \text {-value }=.243 \\
\text { NO }\end{array}$ & $\begin{array}{c}\mathrm{z}=-1.374 \\
\mathrm{p} \text {-value }=.169 \\
\text { NO }\end{array}$ \\
\hline Textura & & 181 & $\begin{array}{c}\mathrm{z}=-.151 \\
\mathrm{p} \text {-value }=.880 \\
\text { NO }\end{array}$ \\
\hline
\end{tabular}

Figura 2. Diferença estatisticamente significativa entre as quatro categorias analisadas sensorialmente da carne de bijupirá (Rachycentron canadum) defumada pelo teste de Friedmann

Nota: YES - indica diferença estatisticamente significativa $(\mathrm{P}<.008)$ entre o escore médio do atributo indicado na respectiva linha e o escore médio do atributo indicado na respectiva coluna; NO - indica inexistência de diferença estatisticamente significativa $(\mathrm{P}>.008)$ entre os escores dos atributos indicados nas respectivas linhas e colunas. 
Tabela 3. Valores médios das notas dadas aos atributos na análise sensorial da carne de bijupirá (Rachycentron canadum) defumada

\begin{tabular}{cc}
\hline Atributos & Média $( \pm$ d.p. $)$ \\
\hline Odor & $5,8( \pm 1,42)^{\mathrm{a}}$ \\
Cor & $6,1( \pm 1,13)^{\mathrm{a}, \mathrm{b}}$ \\
Textura & $6,3( \pm 1,08)^{\mathrm{b}}$ \\
Sabor & $6,2( \pm 1,42)^{\mathrm{b}}$ \\
\hline
\end{tabular}

Letras iguais entre atributos diferentes indicam que os escores não diferem entre si.

De modo distinto, Coelho et al. (2010) não encontraram diferença entre as médias dos atributos avaliados em escala de nove pontos para filés de carpa e tilápia defumados (aparência, aroma, textura e sabor); além disso, as médias se mostraram inferiores (entre gostei moderadamente e gostei ligeiramente) ao do presente trabalho. Igualmente, Costa et al. (2008) não obtiveram diferença significativa entre os atributos aparência, cor, aroma, textura e sabor em filés de piau-vermelho defumados, com médias que também variaram entre gostei moderadamente e gostei ligeiramente. No presente trabalho, além da diferença significativa entre o atributo odor e os atributos textura e sabor, as médias variaram de gostei muito a gostei moderadamente, e apenas a média do odor se apresentou entre gostei moderadamente e gostei ligeiramente.

Em relação às observações apontadas nos atributos, para odor foram registradas diversidades de opiniões positivas e neutras: "odor maravilhoso", "cheiro bom", "agradou bastante", "suave" (2), "normal", "normal de peixe", "lembra bacon", "não possui odor defumado", "pouco cheiro característico", "não senti odor forte"; e negativas: "um pouco forte" (2), "odor não muito agradável e "cheiro de peixe mesmo, não é muito bom”. Para cor, foram consideradas positivas ou neutras as seguintes observações: "aparência bem atraente", "muito bem corado", "aparência agradável" (2), "cor boa" (2), "esteticamente muito bom", "cor bonita", "aparência característica", "carne bem clara"; e negativas: "poderia ter mais coloração", "parece ser muito oleoso". Este último pode ser explicado pelo alto teor de lipídeo do produto.
Para textura, foram atribuídas observações positivas, tais como: "ótima”, "excelente", "muito macio", "bem macio" (2), "macia, se desfaz com facilidade", "gostei da firmeza", "muito boa" (3), "normal", "muito gostoso, sabor diferenciado"; e negativas: "carne um pouco firme", "pouco seco", "um pouco borrachudo", "um pouco oleoso". A oleosidade voltou a ser apontada.

Quanto ao sabor, as opiniões variaram, apresentando comentários positivos, como "amei", "excelente", "gostei muito", "muito bom" (2), "muito saboroso" (3), "maravilhoso', "muito agradável", "bom gosto", "saboroso", "sabor acentuado, levemente defumado", "sal no ponto certo"; e divergentes, como: "resquícios de defumação", "o defumado ficou no odor e não no sabor", "um pouco salgado", "salgado para meu paladar", "achei o gosto forte" e "gosto de óleo". Novamente foi apontada a oleosidade do produto.

Em relação à intenção de compra, foi atribuída a maior porcentagem para decididamente compraria $(40 \%)$, seguido de provavelmente compraria $(38 \%)$; apenas $10 \%$ informaram que provavelmente ou decididamente não comprariam. Esse resultado mostrou-se superior ao de Ferreira et al. (2012), que obtiveram como maior percentual em intenção de compra a segunda escala "provavelmente compraria", ao testarem a aceitabilidade de pintado $(53,33 \%)$ e "catfish" (40\%) defumados por meio da fumaça líquida.

\section{CONCLUSÃO}

O produto elaborado, carne de bijupirá defumada, obteve condições higiênico-sanitárias extremamente satisfatórias, boa qualidade nutricional e alto índice de aceitação sensorial, ressaltando-se os atributos textura e sabor, assim como a grande intenção de compra. Evidenciouse, assim, que esse tipo de processo pode ser realizado em escala artesanal ou industrial, dependendo da produção local.

\section{AGRADECIMENTOS}

À Faperj, pelo apoio financeiro ao projeto; à Capes, pela bolsa de doutoramento; aos funcionários Eduardo da Silva Machado (Fiperj) e Cláudia dos Santos (CMN/UFF), pelo apoio às 
análises; ao CVT- São Gonçalo/Faetec, por disponibilizar o defumador; e aos produtores Carlos Kazuo e Marcelo Lacerda, pela cessão de pescado para a pesquisa.

\section{REFERÊNCIAS}

ACKMAN, R.G. Nutritional composition of fats in seafood. Prog. Food Nutr. Sci., v.13, p.161$241,1989$.

ALMEIDA-MURADIAN, L.B.; PENTEADO, M.V.C. Vigilância sanitária: tópicos sobre legislação e análise de alimentos. Rio de Janeiro: Guanabara Koogan, 2007. 224p.

OFFICIAL methods of analysis of the association of analytical chemists. 15.ed. Washington: AOAC, 1990. 1298p.

BRASIL. Ministério da Agricultura, Pecuária e Abastecimento. Decreto $\mathrm{n}^{\circ} 30.691$, de 29 de março de 1952. Aprova o novo regulamento da inspeção industrial e sanitária de produtos de origem animal. Diário Oficial da União. Brasília, 7 jul. 1952. Seção 1.

BRASIL. Ministério da Saúde. Resolução RDC $\mathrm{n}^{\circ} 12$, de 02 de janeiro de 2001. Aprova o Regulamento Técnico sobre Padrões Microbiológicos para Alimentos. Brasília, DF, 2001.

COELHO, M.I.S.; NETO, L.P.; NASCIMENTO, J.R.; COELHO, M.C.S.C.; LIMA, M.S. Avaliação sensorial de filés de peixes exóticos defumados com e sem codimentação. 2010. Disponível em: $<$ http://congressos.ifal.edu.br/index.php/connepi/ CONNEPI2010/paper/view/1938/94>. Acessado em: 20 jun. 2015.

COSTA, A.P.R.; ANDRADE, D.R.; VIDAL JÚNIOR, M.V. et al. Defumação de filés de piau-vermelho (Leporinus copelandii) com o uso de fumaça líquida. Rev. Ceres, v.55, p.22512257, 2008.

DUTCOSKY, S.D. Análise sensorial de alimentos. Curitiba: Universitária Champagnat, 2011. 531p.

FOOD Labelling: complete texts. Roma: FAO, 2005. (The Codex Alimentarius Commission and the FAO/WHO Food Standards Programme. Special Publications). Available in: <http://www.codexalimentarius.net/web/publicat ions_es.jsp>. Accessed in: 03 Aug. 2007.
FERREIRA, L.O.; PEIXOTO, T.S.; PINEDO, R.A.; ALTEMIO, A.D.C. Avaliação da aceitação pintado (Pseudoplatystoma corruscans) e catfish (Ictalurus punctatu) defumados pelo processo de defumação líquida, 2012. Disponível em: <http://www.gvaa.com.br/revista/index.php/CV ADS/article/view/1480/1407>. Acessado em: 15 jan. 2016.

FOLCH, J.; LEES, M.; SLOANE STANLEY, G.H. A simple method for the isolation and purification of total lipides from animal. J. Biol. Chem., v.226, p.497-509, 1957.

FRANCO, G. Tabela de composição química dos alimentos. 9.ed. São Paulo: Atheneu, 1998. $324 \mathrm{p}$.

GONÇALVES, A.A.; CEZARINI, R. Agregando valor ao pescado de água doce: defumação de filés de jundiá (Rhamdia quelen). Repesca, v.3, p.63-79, 2008

GONÇALVES, A.A.; DANTAS NETO, A.B.; GUILHERME, D.D. et al. Técnicas de processamento e beneficiamento visando agregação de valor do beijupirá, Rachycentron canadum. In: NUNES, A.J.P. Ensaios com o beijupirá, Rachycentron canadum. Fortaleza: Ministério da Pesca e Aquicultura / CNPQ / UFC, 2014. p.167-195

GONÇALVES, A.A.; PRENTICEHERNÁNDEZ, C. Defumação líquida de anchova (Pomatomus saltatrix): efeitos do processamento nas propriedades químicas e microbiológicas. Ciênc. Tecnol. Aliment., v.18, p.438-443, 1998.

MÉTODOS físicoquímicos para análise de alimentos. São Paulo: Instituto Adolfo Lutz, 2008. 1020p.

KAISER, J.B.; HOLT, G.J. Species profile: cobia, Stoneville, Mississippi: Southern Regional Aquaculture Center, 2005. 6p. (SRAC Publication, 7202).

LIAO, I.C.; HUANG, T.S.; TSAI, W.S. et al. Cobia culture in Taiwan: current status and problems. Aquaculture, v.237, p.155-165, 2004.

MORAIS, C.; MACHADO, T.M.; TAVARES, M. et al. Defumaçäo líquida da truta arco-íris (Oncorhynchus mykiss): efeitos do processamento e da estocagem nas propriedades físicas, químicas e sensoriais. Rev. Inst. Adolfo Lutz, v.56, p.43-48, 1996. 
OLIVEIRA, E.C.M.; OLIVEIRA, E.R.; LIMA, L.C.O.; BOAS, E.V.B.V. Composição centesimal do cogumelo do sol (Agaricus blazei). UNIFENAS, v.5, p.169-172, 1999.

SHIAU, C.Y.; CHAI, T. Smoked dogfish processing and its refrigerated storage stability. J. Food Sci., v.50, p.1348-1350, 1985.

SIGURGISLADOTTIR, S.; SIGURGISLADOTTIR, M.S.; TORRISSEN, O. et al. Effects of different salting and smoking processes on the microstructure, the texture and yield of Atlantic salmon (Salmo salar) fillets. Food Res. Int., v.33, p.847-855, 2000.

SOUZA, M.L.R. Processamento do filé e da pele da tilápia do Nilo (Oreochromis niloticus): aspectos tecnológicos, composição centesimal, rendimento, vida útil do filé defumado e testes de resistência da pele curtida. 2003. 169f. Tese (Doutorado em Aquicultura) - Centro de Aquicultura da UNESP, Jaboticabal, SP.
VASCONCELLOS, J.P. Determinante do consumo de pescado na população que frequenta feiras livres do município de Santo André, SP. 2010. 120f. Dissertação (Mestre em Epidemiologia Experimental Aplicada às Zoonoses) - Faculdade de Medicina Veterinária e Zootecnia, Universidade de São Paulo, São Paulo, SP.

$3 \mathrm{M}$ Food Safety Method. 3M ${ }^{\mathrm{TM}}$ Petrifilm $^{\mathrm{TM}}$ Salmonella Express System. Easier Salmonella Detection, Faster Confirmation. It's about time. São Paulo: 3M, 2013.

3M Petrifilm ${ }^{\mathrm{TM}}$. Placa para contagem de E. coli e Coliformes. São Paulo: 3M, 2013a.

$3 \mathrm{M}$ Petrifilm ${ }^{\mathrm{TM}}$. Placa Petrifilm ${ }^{\mathrm{TM}}$ Staph Express para contagem expressa de Staphylococcus aureus. São Paulo: 3M, 2013b. 